\title{
Efficacy and safety of proprotein convertase subtilisin/ kexin type 9 monoclonal antibody in adults with familial hypercholesterolemia
}

\author{
Bin Li ${ }^{1}$, Pan-Pan Hao ${ }^{2}$, Yong Zhang ${ }^{3}$, Rui-Hong Yin ${ }^{4}$, Qing-Zan Kong ${ }^{1}$, Xiao-Jun \\ $\mathrm{Cai}^{1}$, Zhuo Zhao ${ }^{1}$, Jian-Ni Qij ${ }^{5}$, Ying $\mathrm{Li}^{6}$, Jie Xiao ${ }^{2}$, Fu Wang ${ }^{2}$, Wei Yi', Xiao-Ping $\mathrm{Ji}^{2}$ \\ and Guo-Hai Su${ }^{1}$ \\ ${ }^{1}$ Department of Cardiology, Jinan Central Hospital affiliated to Shandong University, Jinan, Shandong, China \\ ${ }^{2}$ Key Laboratory of Cardiovascular Remodeling and Function Research, Chinese Ministry of Education and Chinese Ministry \\ of Health, Department of Cardiology, Shandong University Qilu Hospital, Jinan, Shandong, China \\ ${ }^{3}$ Department of Neurology, Jinan Central Hospital affiliated to Shandong University, Jinan, Shandong, China \\ ${ }^{4}$ Department of Gastroenterology, First People's Hospital of Jinan, Jinan, Shandong, China \\ ${ }^{5}$ Central Laboratory, Shandong Provincial Hospital affiliated to Shandong University, Jinan, Shandong, China \\ ${ }^{6}$ Central Laboratory, Jinan Central Hospital affiliated to Shandong University, Jinan, Shandong, China \\ ${ }^{7}$ Engineering Training Center, Shandong University, Jinan, Shandong, China \\ Correspondence to: Guo-Hai Su, email: guohaisu@medmail.com.cn \\ Keywords: efficacy, safety, proprotein convertase subtilisin/kexin type 9 monoclonal antibody, familial hypercholesterolemia \\ Received: April 27, $2016 \quad$ Accepted: July 10, $2016 \quad$ Published: July 21, 2016
}

Copyright: Li et al. This is an open-access article distributed under the terms of the Creative Commons Attribution License (CC-BY), which permits unrestricted use, distribution, and reproduction in any medium, provided the original author and source are credited.

\section{ABSTRACT}

Proprotein convertase-subtilisin/kexin type 9 (PCSK9) monoclonal antibody is a new therapy to reduce low-density lipoprotein cholesterol (LDL-C) level in patients with familial hypercholesterolemia (FH). This pooled analysis aimed to estimate the efficacy and safety of PCSK9 antibody therapy in FH. Reports of randomized controlled trials (RCTs) comparing PCSK9 antibody to placebo were retrieved by a search of MEDLINE via PubMed, EMBASE, the Cochrane Library databases, ClinicalTrials.gov and Clinical Trial Results (up to November 30, 2015) with no language restriction. Data were abstracted by a standardized protocol. We found eight RCTs $(1,879$ patients with FH) for the pooled analysis. As compared with placebo, PCSK9 antibody therapy remarkably reduced LDL-C level (mean reduction: $\mathbf{- 4 8 . 5 4 \% , 9 5 \% ~ C I : ~}$ -53.19 to -43.88 ), total cholesterol (mean reduction: $-31.08 \%$, $95 \%$ CI: -35.20 to -26.95), lipoprotein (a) (mean reduction: $-20.44 \%, 95 \%$ CI: -25.21 to -15.66 ), and apolipoprotein B (mean reduction: $-36.32 \%, 95 \%$ CI: -40.75 to -31.90 ) and elevated the level of high-density lipoprotein cholesterol (mean change: $6.29 \%$, $95 \%$ CI: 5.12 to 7.46) and apolipoprotein A1(mean change: 4.86\%, $95 \%$ CI: 3.77 to 5.95). Therapy with and without PCSK9 antibodies did not differ in rate of adverse events (pooled rate: $50.86 \%$ vs. $48.63 \%$; RR: 1.03; $95 \%$ CI: 0.92 to $1.15 ; P=0.64$; heterogeneity $P$ $=0.13 ; I^{2}=40 \%$ ) or serious adverse events (pooled rate: $7.14 \%$ vs. $6.74 \%$; RR: 1.05; $95 \%$ CI: 0.70 to $1.58 ; P=0.80$; heterogeneity $P=0.69 ; I^{2}=0 \%$ ). PCSK9 antibody may be an effective and safe treatment for $\mathrm{FH}$.

\section{INTRODUCTION}

Familial hypercholesterolemia $(\mathrm{FH})$ is a genetic disease involved in lipid metabolism caused by mutations in low-density lipoprotein receptor (LDLR), apolipoprotein B (ApoB) and proprotein convertase subtilisin/kexin type 9 (PCSK9) [1]. FH is clinically classified as heterozygous familial hypercholesterolemia $(\mathrm{HeFH})$ and homozygous familial hypercholesterolemia $(\mathrm{HoFH})$ [2]. The characteristics of patients with $\mathrm{FH}$ 
are elevated plasma level of low-density lipoprotein cholesterol (LDL-C) and increased risk of premature coronary heart disease $[3,4]$. Statins are the first-line drugs for treatment of $\mathrm{FH}$ [5], but the guidelines recommending LDL-C goals are not achieved despite high-intensity statin therapy [6]. Combined treatment with high-strength statins and ezetimibe or other drugs may help lower LDL-C levels $[7,8]$, but achieving the treatment targets is difficult $[3,9-11]$. As well, some patients fail to adhere to statins treatment because of its side effects [12].

PCSK9 is a kind of serine protease that is synthesized and secreted by the liver; it is expressed in the liver, small intestine, kidney and nervous system [13, 14]. PCSK9 binds to LDLR for LDLR degradation in lysosomes, which eventually elevates the plasma level of LDL-C $[15,16]$. PCSK9 is connected to dyslipidemia, especially LDL-C metabolism [17], and is closely related to risk of coronary heart disease.

The FH phenotype is caused by gain-of-function mutations in PCSK9 $[3,15]$. Inhibiting PCSK9 has led to potential therapeutic agents for $\mathrm{FH}[15,18-20]$. The use of PCSK9 monoclonal antibodies can reduce circulating LDL-C level in patients with FH and could be synergistic with statins [21].

The efficiency and safety of PCSK9 inhibitor therapy for hypercholesterolemia has been evaluated [22-24], but a pooled analysis of the therapy for $\mathrm{FH}$ is lacking. In addition, the efficacy outcomes for lipids in
FH are inconsistent. Thus, we conducted a pooled analysis of randomized controlled trials (RCTs) to systemically evaluate the efficiency and safety of PCSK9 antibody therapy for $\mathrm{FH}$.

\section{RESULTS}

\section{Study selection and patient characteristics}

Our search retrieved 116 related studies in total; 111 were excluded because they were review articles, letters, animal trials, phase 1 trials, not RCTs, not population with $\mathrm{FH}$, or were not correlated with the present pooled analysis. We included unpublished reports for three clinical trials (ODYSSEY FHI, ODYSSEY FHII and ODYSSEY HIGH FH) (Figure 1). Our final sample included reports for eight studies including 1,879 patients with FH. All eight studies were of good quality (Jadad score $\geq 3$ ).

Characteristics of the eight studies are in the Table 1. One study was of HoFH patients and seven were of $\mathrm{HeFH}$ patients. Two reports were of phase 2 trials and six were of phase 3 trials; Alirocumab was subcutaneously injected as PCSK9 antibody in five studies and evolocumab in three others; Four trials were 12 weeks and four were $>$ 12 weeks long.

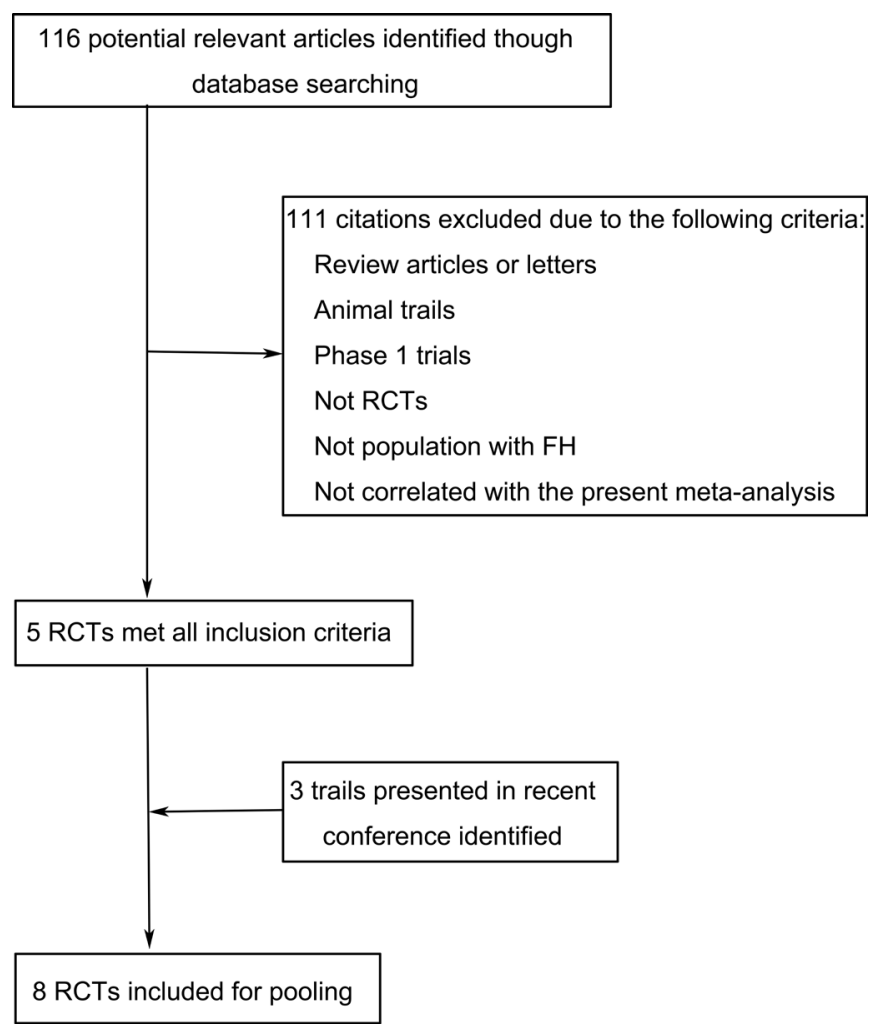

Figure 1: Flow chart for study selection. RCT, randomized controlled trial; FH, familial hypercholesterolemia. 
Table 1: Baseline characteristics of clinical trials.

\begin{tabular}{|c|c|c|c|c|c|c|c|c|c|c|}
\hline Study & Journal, Year & Phase & $\begin{array}{l}\text { Patients, } \\
\text { n }\end{array}$ & $\begin{array}{l}\text { Mean age } \\
(y)\end{array}$ & $\begin{array}{l}\text { Women, } n \\
(\%)\end{array}$ & $\begin{array}{l}\text { Duration } \\
\text { (w) }\end{array}$ & $\begin{array}{l}\text { Investigational } \\
\text { drug and dose }\end{array}$ & Control & Population & $\begin{array}{l}\text { LLT } \\
\text { background }\end{array}$ \\
\hline RUTHERFORD & $\begin{array}{l}\text { Circulation, } \\
2012\end{array}$ & 2 & 167 & $50(13)$ & $79(47)$ & 12 & $\begin{array}{l}\text { Evolocumab } 350 \\
\mathrm{mg} \mathrm{Q4W} \mathrm{and} \\
420 \mathrm{mg} \mathrm{Q} 4 \mathrm{~W}\end{array}$ & Placebo & $\mathrm{HeFH}$ & $\begin{array}{l}\text { Statin } \\
\text { ezetimibe }\end{array}$ \\
\hline TESLA Part B & Lancet, 2014 & 3 & 49 & $31(13)$ & $24(49)$ & 12 & $\begin{array}{l}\text { Evolocumab } 420 \\
\text { mg Q4W }\end{array}$ & Placebo & $\mathrm{HoFH}$ & $\begin{array}{l}\text { Statin } \\
\text { ezetimibe }\end{array}$ \\
\hline RUTHERFORD-2 & Lancet, 2014 & 3 & 329 & $51(14)$ & $139(42)$ & 12 & $\begin{array}{l}\text { Evolocumab } 140 \\
\mathrm{mg} \text { Q2W and } \\
420 \mathrm{mg} \mathrm{Q} 4 \mathrm{~W}\end{array}$ & Placebo & $\mathrm{HeFH}$ & $\begin{array}{l}\text { Statin } \\
\text { ezetimibe }\end{array}$ \\
\hline Stein et al. & Lancet, 2012 & 2 & 77 & $53(10)$ & $30(39)$ & 12 & $\begin{array}{l}\text { Alirocumab 150, } \\
200 \text {, or } 300 \mathrm{mg} \\
\text { Q4W and } 150 \\
\mathrm{mg} \mathrm{Q2W}\end{array}$ & Placebo & $\mathrm{HeFH}$ & $\begin{array}{l}\text { Statin } \\
\text { ezetimibe }\end{array}$ \\
\hline ODYSSEY FH I & $\begin{array}{l}\text { ESC Congress } \\
2014\end{array}$ & 3 & 486 & $52(12)$ & $212(55)$ & 24 & $\begin{array}{l}\text { Alirocumab } \\
75 \text { mg with } \\
\text { potential up- } \\
\text { titration to } 150 \\
\text { mg Q2W }\end{array}$ & Placebo & $\mathrm{HeFH}$ & $\begin{array}{l}\text { Statin } \pm \text { other } \\
\text { LLT }\end{array}$ \\
\hline ODYSSEY FH II & $\begin{array}{l}\text { ESC Congress } \\
2014\end{array}$ & 3 & 249 & $53(13)$ & $118(47)$ & 24 & \begin{tabular}{lr}
\multicolumn{3}{l|}{ Alirocumab } \\
75 mg with \\
potential up- \\
titration to 150 \\
mg Q2W \\
\end{tabular} & Placebo & $\mathrm{HeFH}$ & $\begin{array}{l}\text { Statin } \pm \text { other } \\
\text { LLT }\end{array}$ \\
\hline $\begin{array}{l}\text { ODYSSEY HIGH } \\
\text { FH }\end{array}$ & \begin{tabular}{|l} 
AHA \\
Scientific \\
Sessions 2014
\end{tabular} & 3 & 107 & $52(11)$ & $50(47)$ & 24 & $\begin{array}{l}\text { Alirocumab } 150 \\
\mathrm{mg} \text { Q2W }\end{array}$ & Placebo & $\mathrm{HeFH}$ & $\begin{array}{l}\text { Statin } \pm \text { other } \\
\text { LLT }\end{array}$ \\
\hline $\begin{array}{l}\text { ODYSSEY LONG } \\
\text { TERM }\end{array}$ & NEJM, 2015 & 3 & 2341 & $61(10)$ & $884(38)$ & 24 & $\begin{array}{l}\text { Alirocumab } 150 \\
\text { mg Q2W }\end{array}$ & Placebo & $\mathrm{HeFH}+\mathrm{HC}$ & $\begin{array}{l}\text { Statin } \pm \text { other } \\
\text { LLT }\end{array}$ \\
\hline
\end{tabular}

Data are mean (SD), number (\%); Q2W, every 2 weeks; Q4W, every 4 weeks; HeFH, heterozygous familial hypercholesterolemia; HoFH, homozygous familial hypercholesterolemia; HC, hypercholesterolemia; LLT, lipid-lowering therapy.

\section{Clinical end points}

\section{Efficacy outcomes}

We used all eight reports for the analysis of LDL-C with a random-effects model because of significant heterogeneity $\left(P<0.00001, I^{2}=100 \%\right)$.Level of LDL-C were reduced almost 50\% with than without PCSK9 antibody treatment (mean reduction: $-48.54 \%$, 95\% confidence interval [CI]: -53.19 to -43.88 ) (Table 2). On subgroup analysis, LDL-C level was reduced more in patients with $\mathrm{HeFH}$ than $\mathrm{HoFH}$ (mean reduction: $-51.03 \%$, 95\% CI: -55.59 to -46.48 vs. $-31.00 \%, 95$ $\% \mathrm{CI}:-33.96$ to -28.04$)$. Heterogeneity tests for subgroups showed a striking difference between $\mathrm{HeFH}$ and $\mathrm{HoFH}$ groups $(P<0.00001)$, so the heterogeneity was caused in part by the different populations. However, analyses by type of PCSK9 antibody or duration of treatment did not reveal heterogeneity (Table 3 ).

Seven trials assessed high-density lipoprotein cholesterol (HDL-C), five total cholesterol (TC), six lipoprotein (a) (Lp(a)), six apolipoprotein A1 (ApoA1), seven ApoB and six triglycerides (TG) (Table 2). HDL-C level was significantly increased with PCSK9 antibodies (mean change: $6.29 \%$, 95\% CI: 5.12 to 7.46 ). However, the mean changes in TC, Lp(a), ApoA1, ApoB and TG were $-31.08 \%$ (95\% CI: -35.20 to -26.95$),-20.44 \%(95 \%$ CI: -25.21 to -15.66$), 4.86 \%$ (95\% CI: 3.77 to 5.95 ), $-36.32 \%$ (95\% CI: -40.75 to -31.90$)$ and $-7.92 \%$ (95\% CI: -19.19 to 3.36 ), respectively. We used a random-effects model to analyze HDL-C, TC, Lp(a), ApoA1, ApoB and TG because of the significant heterogeneity (all $P<$ $0.00001, I^{2}=97 \%$ to $100 \%$ ). The changes in lipid levels with and without PCSK9 antibodies were significant, except for a decrease in TG level $(P=0.17)$.

\section{Safety outcomes}

We evaluated the adverse events for the eight trials and compared the data for clinical safety outcomes (Table 2). PCSK9 antibody treatment for $\mathrm{FH}$ did not increase the rate of adverse events (pooled rate: $50.86 \%$ vs. 48.63\%; pooled relative risk [RR]: $1.03 ; 95 \% \mathrm{CI}: 0.92$ to $1.15 ; P=$ 0.64 ; heterogeneity $P=0.13 ; I^{2}=40 \%$ ) or serious adverse events (pooled rate: $7.14 \%$ vs. 6.74\%; RR: 1.05 ; 95\% CI: 0.70 to $1.58 ; P=0.80$; heterogeneity $P=0.69 ; I^{2}=0 \%$ ) as compared with placebo. The incidence of increased aspartate aminotransferase or alanine aminotransferase (AST or ALT) level greater than three times the upper limit of normal (ULN) did not differ with and without PCSK9 antibody (pooled rate: $0.94 \%$ vs. $0.51 \%$; RR: 1.49 ; 95\% CI: 0.24 to $9.10 ; P=0.67$; heterogeneity $P=0.62 ; I^{2}$ 
Table 2: Pooled-analysis results of the percentage change in level of serum lipid and the incidence of adverse events.

\begin{tabular}{|l|l|l|l|l|l|}
\hline Outcomes & $\begin{array}{l}\text { Patients, } \\
\text { n }\end{array}$ & WMD/RR (95\% CI) & $P$ value & $\boldsymbol{I}^{2} \boldsymbol{\%}$ & $\begin{array}{l}\text { Heterogeneity } \\
\boldsymbol{P} \text { value }\end{array}$ \\
\hline LDL-C & 1875 & $-48.54 \%[-53.19,-43.88]$ & $P<0.00001$ & $100 \%$ & $P<0.00001$ \\
\hline HDL-C & 1460 & $6.29 \%[5.12,7.46]$ & $P<0.00001$ & $97 \%$ & $P<0.00001$ \\
\hline TC & 1082 & $-31.08 \%[-35.20,-26.95]$ & $P<0.00001$ & $99 \%$ & $P<0.00001$ \\
\hline Lp(a) & 1383 & $-20.44 \%[-25.21,-15.66]$ & $P<0.00001$ & $100 \%$ & $P<0.00001$ \\
\hline ApoA1 & 1392 & $4.86 \%[3.77,5.95]$ & $P<0.00001$ & $97 \%$ & $P<0.00001$ \\
\hline ApoB & 1438 & $-36.32 \%[-40.75,-31.90]$ & $P<0.00001$ & $100 \%$ & $P<0.00001$ \\
\hline TG & 1383 & $-7.92 \%[-19.19,3.36]$ & $P=0.17$ & $100 \%$ & $P<0.00001$ \\
\hline Adverse events & 1462 & $1.03[0.92,1.15]$ & $P=0.64$ & $40 \%$ & $P=0.13$ \\
\hline Serious adverse events & 1385 & $1.05[0.70,1.58]$ & $P=0.80$ & $0 \%$ & $P=0.69$ \\
\hline Discontinuation & 545 & $1.01[0.09,10.89]$ & $P=0.99$ & $\mathrm{NA}$ & $\mathrm{NA}$ \\
\hline Death & 545 & $\mathrm{NE}$ & $\mathrm{NA}$ & $\mathrm{NA}$ & $\mathrm{NA}$ \\
\hline Headache & 1301 & $0.83[0.49,1.38]$ & $P=0.46$ & $0 \%$ & $P=0.86$ \\
\hline Injection site reactions & 1421 & $1.43[0.93,2.21]$ & $P=0.10$ & $0 \%$ & $P=0.66$ \\
\hline Nasopharyngitis & 1385 & $1.09[0.78,1.54]$ & $P=0.61$ & $31 \%$ & $P=0.20$ \\
\hline Gastroenteritis & 571 & $1.15[0.49,2.66]$ & $P=0.75$ & $31 \%$ & $P=0.22$ \\
\hline Nausea & 652 & $0.67[0.28,1.62]$ & $P=0.37$ & $47 \%$ & $P=0.13$ \\
\hline $\begin{array}{l}\text { Upper respiratory tract } \\
\text { infections }\end{array}$ & 701 & $1.03[0.53,1.99]$ & $P=0.93$ & $0 \%$ & $P=0.37$ \\
\hline AST or ALT>3ULN & 622 & $1.49[0.24,9.10]$ & $P=0.67$ & $0 \%$ & $P=0.62$ \\
\hline CK>5ULN & 622 & $0.63[0.17,2.29]$ & $P=0.48$ & $28 \%$ & $P=0.25$ \\
\hline
\end{tabular}

WMD, weighted mean difference; RR, risk ratio; CI, confidence interval; LDL-C, low-density lipoprotein cholesterol; HDL-C, high-density lipoprotein cholesterol; TC, total cholesterol; Lp(a), lipoprotein(a); ApoA1, apolipoprotein A1; ApoB, apolipoprotein B; TG, triglycerides; AST, aspartate aminotransferase; ALT, alanine aminotransferase; CK, creatine kinase; ULN, upper limit of normal; NA, not applicable; NE, not estimable.

$=0 \%)$. The pooled incidence of increased creatine kinase (CK) level greater than five times the ULN was similar with the two treatments(pooled rate: $0.94 \%$ vs. $1.53 \%$; RR: $0.63 ; 95 \%$ CI: 0.17 to $2.29 ; P=0.48$; heterogeneity $P$ $=0.25 ; I^{2}=28 \%$ ). In addition, for other adverse events, the rates of nasopharyngitis, headache, gastroenteritis, upper respiratory tract infections and injection-site reactions were greater but not significantly with than without PCSK9 antibodies.

\section{Sensitivity/subgroup analyses}

Sensitivity analysis was used to determine whether exclusion of any single study altered pooled RRs or weighted mean differences (WMDs). We found no heterogeneity for safety outcomes but found heterogeneity for efficacy outcomes, which was not addressed well by sensitivity analysis. Then, we performed subgroup analysis of changes in lipid and apolipoprotein levels after PCSK9 antibody treatment by different PCSK9 antibodies, types of FH and duration of treatment and found that the heterogeneity was caused in part by the different types of $\mathrm{FH}$.

\section{Publication bias}

We calculated $\mathrm{N}_{\mathrm{fs} 0.05}$ to estimate the publication bias for each comparison and found $\mathrm{N}_{\mathrm{fs} 0.05}$ values were greater than the number of studies except for incidence of serious adverse events, death, discontinuation, headache, upper respiratory tract infections and increased AST/ALT and CK included in the pooled analysis. The $\mathrm{N}_{\mathrm{fs} 0.05}$ value for several safety outcomes was smaller than the number of included studies, which may be consistent with "small study" bias.

\section{DISCUSSION}

To our knowledge, this is the first pooled analysis of studies comparing the efficiency and safety of PCSK9 antibodies to no anti-PCSK9 antibodies for FH. Treatment with PCSK9 antibodies was associated with significantly reduced levels of LDL-C, TC, ApoB, and Lp(a) and elevated levels of HDL-C and ApoA1 in FH patients, with no difference in adverse events or serious adverse events with and without treatment.

In eight phase 2 and phase 3 trials that were eligible for the pooled analysis (1,879 FH patients) [25-29], the clinical adverse events with PCSK9 antibody treatment 
Table 3: Subgroup analyses with regard to the percentage change in plasma level of LDL-C.

\begin{tabular}{|l|l|l|l|l|l|l|}
\hline Subgroup & $\begin{array}{l}\text { Patients, } \\
\mathbf{n}\end{array}$ & $\mathbf{W M D}(\mathbf{9 5 \%} \mathbf{C I})$ & $\boldsymbol{P}$ value & $\boldsymbol{I}^{\mathbf{2}} \mathbf{\%}$ & $\begin{array}{l}\text { Heterogeneity } \\
\boldsymbol{P} \text { value }\end{array}$ & $\begin{array}{l}\boldsymbol{P} \text { value for subgroup } \\
\text { differences }\end{array}$ \\
\hline $\begin{array}{l}\text { Adjustment for type } \\
\text { of FH }\end{array}$ & & & & & $P<0.00001$ \\
\hline HeFH & 1826 & $-51.03 \%[-55.59,-46.48]$ & $P<0.00001$ & $100 \%$ & $P<0.00001$ & \\
\hline HoFH & 49 & $-31.00 \%[-33.96,-28.04]$ & $P<0.00001$ & NA & NA & \\
\hline $\begin{array}{l}\text { Adjustment for type } \\
\text { of PCSK9 antibody }\end{array}$ & & & & & & $P=0.78$ \\
\hline Alirocumab & 1330 & $-49.28 \%[-54.95,-43.60]$ & $P<0.00001$ & $100 \%$ & $P<0.00001$ & \\
\hline Evolocumab for & 545 & $-47.21 \%[-60.28,-34.15]$ & $P<0.00001$ & $99 \%$ & $P<0.00001$ & \\
\hline $\begin{array}{l}\text { Adjustment } \\
\text { duration of treatment }\end{array}$ & & & & & $P=0.17$ \\
\hline$\leq 12$ weeks & 622 & $-43.54 \%[-55.57,-31.51]$ & $P<0.00001$ & $99 \%$ & $P<0.00001$ & \\
\hline$>12$ weeks & 1253 & $-53.02 \%[-59.05,-47.00]$ & $P<0.00001$ & $100 \%$ & $P<0.00001$ & \\
\hline
\end{tabular}

LDL-C, low-density lipoprotein cholesterol; WMD, weighted mean difference; CI, confidence interval; FH, familial hypercholesterolemia; HeFH, heterozygous familial hypercholesterolemia; HoFH, homozygous familial hypercholesterolemia; PCSK9, proprotein convertase subtilisin/kexin type 9; NA, not applicable.

mainly concerned headache, injection-site reactions, nasopharyngitis, gastroenteritis, nausea, and upper respiratory tract infections. The total rate of adverse events or serious adverse events with treatment did not differ from the control rate. As well, laboratory analyses, including increased ALT/AST ( $>3 \mathrm{ULN})$ or $\mathrm{CK}(>$ $5 \mathrm{ULN}$ ) levels, did not reveal a significant difference in safety issues between the two treatments. Therefore, on the strength of available data, PCSK9 antibody therapy for FH seems safe and tolerated, but more standardized trials and clinical trials are needed to further verify the safety.

We found great heterogeneity in lipid profile analyses of patients with PCSK9 antibody treatment. On sensitivity and subgroup analyses, the heterogeneity was partly caused by the different types of $\mathrm{FH}(\mathrm{HoFH}$ or $\mathrm{HeFH}$ ). Usually, patients with $\mathrm{HeFH}$ at least have one normal LDLR allele [3], but in HoFH patients, two LDLR alleles are abnormal [30]. Most HoFH patients are compound heterozygotes with defective LDLR-alleles [31] and others are LDLR-negative. PCSK9 antibodies might be more efficacious in reducing LDL-C level in FH patients with residual LDLR function.

$\mathrm{FH}$ is caused by loss-of-function mutations in the LDLR gene, leading to cell uptake of plasma LDL-C blocked by the liver and highly increased serum LDL-C level [3, 32]. Elevated LDL-C level, which is associated with atherosclerosis in affected arteries, is a major risk factor for the occurrence and development of coronary artery disease $[33,34]$. Statins reduce the plasma concentration of LDL-C by increasing the hepatic expression of LDLR and removing LDL in circulation. At present, intensive statin therapy is widely indicated as firstline therapy in $\mathrm{FH}$ [3] to reduce serum LDL-C level and the risk of coronary artery disease [35]. However, despite high-intensity statin therapy, achieving the recommended treatment targets of LDL-C to prevent cardiovascular events is difficult in most patients with $\mathrm{FH}[3,11,36]$. About $10 \%$ of patients are unable to tolerate high-intensity statins because of the side effects [37-39].

In recent years, combined treatment with statins and other lipid-lowering drugs has been a good therapeutic strategy to further reduce LDL-C levels for patients with FH [40]; the monoclonal antibody against PCSK9 is an innovative lipid-lowering drug. In our pooled-analysis of phase 2 and phase 3 clinical trials, treatment with PCSK9 antibodies combined with statins for $\mathrm{FH}$, was effective in reducing LDL-C level, with few side effects [25-29].In addition, statin therapy upregulates serum PCSK9 levels $[15,41,42]$, and treatment with PCSK9 antibodies might strengthen statins to lower LDL-C level. So combined treatment with PCSK9 antibodies and statins may have a synergistic effect in lowering LDL-C level.

The RUTHERFORD-2 trial involved $329 \mathrm{HeFH}$ patients with statins, with or without ezetimibe, randomly assigned to receive evolocumab $140 \mathrm{mg}$ subcutaneously every 2 weeks or $420 \mathrm{mg}$ every 4 weeks or placebo [26]. Compared with placebo, treatment with evolocumab biweekly or monthly led to $59.2 \%$ and $61.3 \%$ reduction in mean LDL-C level, respectively, after 12 weeks.

In the trial of Stein and colleagues, the efficacy and tolerability of alirocumab were evaluated in 77 patients with $\mathrm{HeFH}$ in the United States and Canada [27]. Alirocumab at 150 to $300 \mathrm{mg}$ was found generally safe and efficacious. As well, alirocumab dose-dependently reduced LDL-C level by $28.9 \%$ to $67.9 \%$ versus $10.7 \%$ in the placebo group.

The TESLA Part B trial included 50 patients with HoFH who received evolocumab $420 \mathrm{mg}$ or placebo every 4 weeks for 12 weeks; 49 patients actually received the study drug and completed the study [28]. Treatment with evolocumab significantly reduced LDL-C level by $30.9 \%$ as compared with placebo. 
Moreover, in our analysis, other lipid levels were modified by PCSK9 antibody, including significant decreases in $\mathrm{Lp}(\mathrm{a}), \mathrm{TC}$ and $\mathrm{ApoB}$ levels and increase in HDL-C and ApoA1 levels. In addition, TG level was changed, although not significantly. The change in lipid profile is not conducive to the occurrence and development of atherosclerosis [43].

In patients with $\mathrm{FH}$, PCSK9 antibody therapy satisfactorily regulates lipid levels, especially reducing serum level of LDL-C. Our pooled analysis revealed the good safety and tolerant profile with short-term administration of PCSK9 antibodies for FH. Results of ongoing trials of PCSK9 antibodies for FH, to evaluate the efficiency, safety and clinical outcomes with long-term treatment, are awaited.

\section{MATERIALS AND METHODS}

This pooled analysis was conducted following the preferred reporting items of the systematic reviews and meta-analysis (PRISMA) statement. [44]

\section{Selection criteria}

Studies were eligible for the pooled analysis if they 1) were RCTs, 2) involved human subjects with $\mathrm{FH}$, and 3) compared PCSK9 antibody to no PCSK9 antibody regardless of other lipid-lowering therapy. Studies not meeting these criteria, non-clinical studies, non-RCTs and studies without complete data were excluded.

\section{Search sources and strategy}

We performed a literature search of MEDLINE via PubMed, EMBASE, the Cochrane Library databases, ClinicalTrials.gov and Clinical Trial Results (www .clinicaltrialresults.org) for reports of clinical trials and RCTs published in any language up to November 30, 2015, by using the following keywords: "PCSK9" or "proprotein convertase subtilisin/kexin type 9" or "bococizumab" or "AMG 145" or "evolocumab" or 'REGN727" or "SAR236553" or "alirocumab" and "familial hypercholesterolemia". Reference lists of relevant trials and reviews were manually checked for additional reports.

\section{Data management and quality assessment}

Abstracted data included first author's name, year of publication, study design, number of enrolled patients, follow-up duration, baseline characteristics of patients, drug interventions, clinical outcomes and adverse events. We recorded percentage change in lipid and apolipoprotein levels after treatment with PCSK9 antibody as the primary end point. The incidence of adverse events was a secondary end point.

Two reviewers (BL and $\mathrm{PPH}$ ) assessed report eligibility and abstracted data independently by using a standardized report form and evaluated the quality of reports independently following the Jadad scale [45]. Any discrepancies were resolved by consensus.

\section{Statistical analysis}

The pooled analysis involved use of REVMAN 5.3. Heterogeneity among studies was tested by the Cochran $\mathrm{Q}$ test and $I^{2}$ test. A fixed-effects or random-effects model was applied depending on the heterogeneity results [46]: with lack of heterogeneity $\left(P>0.10\right.$ or $\left.I^{2}<50 \%\right)$, the fixed-effects model was used, and with significant heterogeneity $\left(P<0.10\right.$ or $\left.I^{2}>50 \%\right)$, the random-effects model was used. Two-tailed $P<0.05$ was considered statistically significant, and RR or WMD was reported with $95 \%$ CIs. Furthermore, we performed sensitivity and subgroup analyses to lessen the influence of heterogeneity by removing an individual trial or classifying the studies based on similar features. Finally, publication bias was assessed by the fail-safe number $\left(\mathrm{N}_{\mathrm{fs}}\right)$ : risk of publication bias was suggested if the calculated $\mathrm{N}_{\mathrm{fs}}$ was less than the number of observed studies. The $\mathrm{N}_{\mathrm{fs} 0.05}$ was calculated as $\mathrm{N}_{\text {fs } 0.05}=\left(\sum \mathrm{Z} / 1.64\right)^{2}-k$, where " $k$ " is the number of studies in the pooled analysis.

\section{ACKNOWLEDGMENTS}

This work was supported by the National Natural Science Foundation of China [81170087], the National Natural Science Foundation of China [81400284], the Natural Science Foundation of Shandong Province [ZR2014HM044, ZR2014HP045], the Promotive research fund for excellent young and middle-aged scientists of Shandong Province [BS2014YY037] and the ischemic heart disease research and innovation team of Jinan City.

\section{CONFLICTS OF INTEREST}

The authors declare no conflict of interest.

\section{REFERENCES}

1. Maxwell KN and Breslow JL. Proprotein convertase subtilisin kexin 9: the third locus implicated in autosomal dominant hypercholesterolemia. Curr Opin Lipidol. 2005; 16: $167-72$.

2. Khachadurian AK. The Inheritance of Essential Familial Hypercholesterolemia. Am J Med. 1964; 37: 402-7.

3. Nordestgaard BG, Chapman MJ, Humphries SE, Ginsberg HN, Masana L, Descamps OS, Wiklund O, Hegele RA, Raal FJ, Defesche JC, Wiegman A, Santos RD, Watts GF, 
et al. Familial hypercholesterolaemia is underdiagnosed and undertreated in the general population: guidance for clinicians to prevent coronary heart disease: consensus statement of the European Atherosclerosis Society. Eur Heart J. 2013; 34: 3478-90a. doi: 10.1093/eurheartj/eht273

4. Benn M, Watts GF, Tybjaerg-Hansen A and Nordestgaard BG. Familial hypercholesterolemia in the danish general population: prevalence, coronary artery disease, and cholesterol-lowering medication. J Clin Endocrinol Metab. 2012; 97: 3956-64. doi: 10.1210/jc.2012-1563

5. Alonso R, Mata P, Zambon D, Mata N and FuentesJimenez F. Early diagnosis and treatment of familial hypercholesterolemia: improving patient outcomes. Expert Rev Cardiovasc Ther. 2013; 11: 327-42. doi: 10.1586/ erc. 13.7

6. Waters DD, Brotons C, Chiang CW, Ferrieres J, Foody J, Jukema JW, Santos RD, Verdejo J, Messig M, Mcpherson R, Seung KB and Tarasenko L. Lipid treatment assessment project 2: a multinational survey to evaluate the proportion of patients achieving low-density lipoprotein cholesterol goals. Circulation. 2009; 120: 28-34. doi: 10.1161/ CIRCULATIONAHA.108.838466

7. Williams RR, Hunt SC, Schumacher MC, Hegele RA, Leppert MF, Ludwig EH and Hopkins PN. Diagnosing heterozygous familial hypercholesterolemia using new practical criteria validated by molecular genetics. Am J Cardiol. 1993; 72: 171-6.

8. Raal FJ, Pilcher GJ, Panz VR, Van Deventer HE, Brice $\mathrm{BC}$, Blom DJ and Marais AD. Reduction in mortality in subjects with homozygous familial hypercholesterolemia associated with advances in lipid-lowering therapy. Circulation. 2011; 124: 2202-7. doi: 10.1161/ CIRCULATIONAHA.111.042523

9. Pijlman AH, Huijgen R, Verhagen SN, Imholz BP, Liem AH, Kastelein JJ, Abbink EJ, Stalenhoef AF and Visseren FL. Evaluation of cholesterol lowering treatment of patients with familial hypercholesterolemia: a large cross-sectional study in The Netherlands. Atherosclerosis. 2010; 209: 18994. doi: 10.1016/j.atherosclerosis.2009.09.014

10. Goldberg AC, Hopkins PN, Toth PP, Ballantyne CM, Rader DJ, Robinson JG, Daniels SR, Gidding SS, De Ferranti SD, Ito MK, Mcgowan MP, Moriarty PM, Cromwell WC, et al. Familial hypercholesterolemia: screening, diagnosis and management of pediatric and adult patients: clinical guidance from the National Lipid Association Expert Panel on Familial Hypercholesterolemia. J Clin Lipidol. 2011; 5: 133-40. doi: 10.1016/j.jacl.2011.03.001

11. Watts GF, Gidding S, Wierzbicki AS, Toth PP, Alonso R, Brown WV, Bruckert E, Defesche J, Lin KK, Livingston M, Mata P, Parhofer KG, Raal FJ, et al. Integrated guidance on the care of familial hypercholesterolaemia from the International FH Foundation. Int J Cardiol. 2014; 171: 30925. doi: 10.1016/j.ijcard.2013.11.025

12. Dadu RT and Ballantyne CM. Lipid lowering with PCSK9 inhibitors. Nat Rev Cardiol. 2014; 11: 563-75. doi: 10.1038/ nrcardio.2014.84

13. Seidah NG, Benjannet S, Wickham L, Marcinkiewicz J, Jasmin SB, Stifani S, Basak A, Prat A and Chretien M. The secretory proprotein convertase neural apoptosis-regulated convertase 1 (NARC-1): liver regeneration and neuronal differentiation. Proc Natl Acad Sci U S A. 2003; 100: 92833. doi: 10.1073/pnas.0335507100

14. Naureckiene S, Ma L, Sreekumar K, Purandare U, Lo CF, Huang Y, Chiang LW, Grenier JM, Ozenberger BA, Jacobsen JS, Kennedy JD, Distefano PS, Wood A, et al. Functional characterization of Narc 1, a novel proteinase related to proteinase K. Arch Biochem Biophys. 2003; 420: 55-67.

15. Horton JD, Cohen JC and Hobbs HH. PCSK9: a convertase that coordinates LDL catabolism. J Lipid Res. 2009; 50 Suppl: S172-7. doi: 10.1194/jlr.R800091-JLR200

16. Qian YW, Schmidt RJ, Zhang Y, Chu S, Lin A, Wang H, Wang X, Beyer TP, Bensch WR, Li W, Ehsani ME, Lu D, Konrad RJ, et al. Secreted PCSK9 downregulates low density lipoprotein receptor through receptor-mediated endocytosis. J Lipid Res. 2007; 48: 1488-98. doi: 10.1194/ jlr.M700071-JLR200

17. Welder G, Zineh I, Pacanowski MA, Troutt JS, Cao G and Konrad RJ. High-dose atorvastatin causes a rapid sustained increase in human serum PCSK9 and disrupts its correlation with LDL cholesterol. J Lipid Res. 2010; 51: 2714-21. doi: 10.1194/jlr.M008144

18. Cohen JC, Boerwinkle E, Mosley TH, Jr. and Hobbs HH. Sequence variations in PCSK9, low LDL, and protection against coronary heart disease. N Engl J Med. 2006; 354: 1264-72. doi: 10.1056/NEJMoa054013

19. Abifadel M, Varret M, Rabes JP, Allard D, Ouguerram K, Devillers M, Cruaud C, Benjannet S, Wickham L, Erlich D, Derre A, Villeger L, Farnier M, Bet al. Mutations in PCSK9 cause autosomal dominant hypercholesterolemia. Nat Genet. 2003; 34: 154-6. doi: 10.1038/ng1161

20. Willer CJ, Sanna S, Jackson AU, Scuteri A, Bonnycastle LL, Clarke R, Heath SC, Timpson NJ, Najjar SS, Stringham HM, Strait J, Duren WL, Maschio A, et al. Newly identified loci that influence lipid concentrations and risk of coronary artery disease. Nat Genet. 2008; 40: 161-9. doi: 10.1038/ ng.76

21. Dubuc G, Chamberland A, Wassef H, Davignon J, Seidah NG, Bernier L and Prat A. Statins upregulate PCSK9, the gene encoding the proprotein convertase neural apoptosis-regulated convertase-1 implicated in familial hypercholesterolemia. Arterioscler Thromb Vasc Biol. 2004; 24: 1454-9. doi: 10.1161/01. ATV.0000134621.14315.43

22. Zhang XL, Zhu QQ, Zhu L, Chen JZ, Chen QH, Li GN, Xie J, Kang LN and Xu B. Safety and efficacy of anti-PCSK9 antibodies: a meta-analysis of 25 randomized, controlled trials. BMC Med. 2015; 13: 123. doi: 10.1186/s12916-0150358-8 
23. Li C, Lin L, Zhang W, Zhou L, Wang H, Luo X, Luo H, Cai $\mathrm{Y}$ and Zeng C. Efficiency and safety of proprotein convertase subtilisin/kexin 9 monoclonal antibody on hypercholesterolemia: a meta-analysis of 20 randomized controlled trials. J Am Heart Assoc. 2015; 4: e001937. doi: 10.1161/JAHA.115.001937

24. Navarese EP, Kolodziejczak M, Schulze V, Gurbel PA, Tantry U, Lin Y, Brockmeyer M, Kandzari DE, Kubica JM, D'agostino RB Sr, Kubica J, Volpe M, Agewall S, et al. Effects of Proprotein Convertase Subtilisin/Kexin Type 9 Antibodies in Adults With Hypercholesterolemia: A Systematic Review and Meta-analysis. Ann Intern Med. 2015; 163: 40-51. doi: 10.7326/M14-2957

25. Raal F, Scott R, Somaratne R, Bridges I, Li G, Wasserman $\mathrm{SM}$ and Stein EA. Low-density lipoprotein cholesterollowering effects of AMG 145, a monoclonal antibody to proprotein convertase subtilisin/kexin type 9 serine protease in patients with heterozygous familial hypercholesterolemia: the Reduction of LDL-C with PCSK9 Inhibition in Heterozygous Familial Hypercholesterolemia Disorder (RUTHERFORD) randomized trial. Circulation. 2012; 126: 2408-17. doi: 10.1161/CIRCULATIONAHA.112.144055

26. Raal FJ, Stein EA, Dufour R, Turner T, Civeira F, Burgess L, Langslet G, Scott R, Olsson AG, Sullivan D, Hovingh GK, Cariou B, Gouni-Berthold I, et al. PCSK9 inhibition with evolocumab (AMG 145) in heterozygous familial hypercholesterolaemia (RUTHERFORD-2): a randomised, double-blind, placebo-controlled trial. Lancet. 2015; 385: 331-40. doi: 10.1016/S0140-6736(14)61399-4

27. Stein EA, Gipe D, Bergeron J, Gaudet D, Weiss R, Dufour $\mathrm{R}, \mathrm{Wu} \mathrm{R}$ and Pordy R. Effect of a monoclonal antibody to PCSK9, REGN727/SAR236553, to reduce low-density lipoprotein cholesterol in patients with heterozygous familial hypercholesterolaemia on stable statin dose with or without ezetimibe therapy: a phase 2 randomised controlled trial. Lancet. 2012; 380: 29-36. doi: 10.1016/S01406736(12)60771-5

28. Raal FJ, Honarpour N, Blom DJ, Hovingh GK, Xu F, Scott R, Wasserman SM and Stein EA. Inhibition of PCSK9 with evolocumab in homozygous familial hypercholesterolaemia (TESLA Part B): a randomised, double-blind, placebocontrolled trial. Lancet. 2015; 385: 341-50. doi: 10.1016/ S0140-6736(14)61374-X

29. Robinson JG, Farnier M, Krempf M, Bergeron J, Luc G, Averna M, Stroes ES, Langslet G, Raal FJ, El Shahawy M, Koren MJ, Lepor NE, Lorenzato C, et al. Efficacy and safety of alirocumab in reducing lipids and cardiovascular events. N Engl J Med. 2015; 372: 1489-99. doi: 10.1056/ NEJMoa1501031

30. Raal FJ and Santos RD. Homozygous familial hypercholesterolemia: current perspectives on diagnosis and treatment. Atherosclerosis. 2012; 223: 262-8. doi: 10.1016/j.atherosclerosis.2012.02.019

31. Usifo E, Leigh SE, Whittall RA, Lench N, Taylor A, Yeats C, Orengo CA, Martin AC, Celli J and Humphries
SE. Low-density lipoprotein receptor gene familial hypercholesterolemia variant database: update and pathological assessment. Ann Hum Genet. 2012; 76: 387 401. doi: 10.1111/j.1469-1809.2012.00724.x

32. Austin MA, Hutter CM, Zimmern RL and Humphries SE. Genetic causes of monogenic heterozygous familial hypercholesterolemia: a HuGE prevalence review. Am J Epidemiol. 2004; 160: 407-20. doi: 10.1093/aje/kwh236

33. Stone NJ, Levy RI, Fredrickson DS and Verter J. Coronary artery disease in 116 kindred with familial type II hyperlipoproteinemia. Circulation. 1974; 49: 476-88.

34. Risk of fatal coronary heart disease in familial hypercholesterolaemia. Scientific Steering Committee on behalf of the Simon Broome Register Group. BMJ. 1991; 303: 893-6.

35. Versmissen J, Oosterveer DM, Yazdanpanah M, Defesche JC, Basart DC, Liem AH, Heeringa J, Witteman JC, Lansberg PJ, Kastelein JJ and Sijbrands EJ. Efficacy of statins in familial hypercholesterolaemia: a long term cohort study. BMJ. 2008; 337: a2423. doi: 10.1136/bmj.a2423

36. Huijgen R, Kindt I, Verhoeven SB, Sijbrands EJ, Vissers MN, Kastelein JJ and Hutten BA. Two years after molecular diagnosis of familial hypercholesterolemia: majority on cholesterol-lowering treatment but a minority reaches treatment goal. PLoS One. 2010; 5: e9220. doi: 10.1371/ journal.pone.0009220

37. Larosa JC, Pedersen TR, Somaratne R and Wasserman SM. Safety and effect of very low levels of low-density lipoprotein cholesterol on cardiovascular events. Am J Cardiol. 2013; 111: 1221-9. doi: 10.1016/j. amjcard.2012.12.052

38. Rosenbaum D, Dallongeville J, Sabouret P and Bruckert E. Discontinuation of statin therapy due to muscular side effects: a survey in real life. Nutr Metab Cardiovasc Dis. 2013; 23: 871-5. doi: 10.1016/j.numecd.2012.04.012

39. Banach M, Rizzo M, Toth PP, Farnier M, Davidson MH, Al-Rasadi K, Aronow WS, Athyros V, Djuric DM, Ezhov MV, Greenfield RS, Hovingh GK, Kostner K, et al. Statin intolerance - an attempt at a unified definition. Position paper from an International Lipid Expert Panel. Arch Med Sci. 2015; 11: 1-23. doi: 10.5114/aoms.2015.49807

40. Davidson MH, Mcgarry T, Bettis R, Melani L, Lipka LJ, Lebeaut AP, Suresh R, Sun S and Veltri EP. Ezetimibe coadministered with simvastatin in patients with primary hypercholesterolemia. J Am Coll Cardiol. 2002; 40: 2125 34.

41. Awan Z, Seidah NG, Macfadyen JG, Benjannet S, Chasman DI, Ridker PM and Genest J. Rosuvastatin, proprotein convertase subtilisin/kexin type 9 concentrations, and LDL cholesterol response: the JUPITER trial. Clin Chem. 2012; 58: 183-9. doi: 10.1373/clinchem.2011.172932

42. Careskey HE, Davis RA, Alborn WE, Troutt JS, Cao G and Konrad RJ. Atorvastatin increases human serum levels of proprotein convertase subtilisin/kexin type 9. J Lipid Res. 
2008; 49: 394-8. doi: 10.1194/jlr.M700437-JLR200

43. Willeit P, Kiechl S, Kronenberg F, Witztum JL, Santer P, Mayr M, Xu Q, Mayr A, Willeit J and Tsimikas S. Discrimination and net reclassification of cardiovascular risk with lipoprotein(a): prospective 15-year outcomes in the Bruneck Study. J Am Coll Cardiol. 2014; 64: 851-60. doi: 10.1016/j.jacc.2014.03.061

44. Moher D, Liberati A, Tetzlaff J and Altman DG. Preferred reporting items for systematic reviews and meta-analyses: the PRISMA statement. J Clin Epidemiol. 2009; 62: 100612. doi: 10.1016/j.jclinepi.2009.06.005

45. Jadad AR, Moore RA, Carroll D, Jenkinson C, Reynolds DJ, Gavaghan DJ and Mcquay HJ. Assessing the quality of reports of randomized clinical trials: is blinding necessary? Control Clin Trials. 1996; 17: 1-12.

46. Dersimonian R and Laird N. Meta-analysis in clinical trials. Control Clin Trials. 1986; 7: 177-88. 